\title{
Representation of age identities in on-line discourse
}

\author{
Mei-Chen Lin ${ }^{\mathrm{a}, *}$, Mary Lee Hummert ${ }^{\mathrm{b}}$, Jake Harwood ${ }^{\mathrm{c}}$ \\ ${ }^{a}$ School of Communication Studies, Kent State University, P.O. Box 5190, Kent, OH 44242-0001, USA \\ ${ }^{\mathrm{b}}$ Department of Communication Studies at the University of Kansas, USA \\ ${ }^{\mathrm{c}}$ Department of Communication at the University of Arizona, USA
}

\begin{abstract}
This study examines how age identities are presented in an on-line discussion forum for older adults. On-line messages $(N=550)$ were examined using discourse and content analyses. Evidence of a tension between positive and negative age identities emerged in the analysis. Positive themes included a mind-over-body attitude, active engagement, wisdom and maturity, and the freedom of age. Negative themes involved physical decline, a sense of loss, and resistance to aging. Positive age identity themes were more frequently presented in these on-line messages than negative themes, and health-related messages were the most common. The central communication features and framing tactics of each age identity theme are discussed. Implications for theoretical perspectives on discourse and social identity, the limitations of this study, and directions for future research are addressed.

(C) 2004 Elsevier Inc. All rights reserved.
\end{abstract}

Keywords: Age identity; Old people; Discourse analysis; On-line discussion forum; Social identity theory

\section{Introduction}

Viewing later life across its full range-old age as healthy but also infirm, potentially a time of fulfillment but for many a time of deprivation and anxiety - may at least succeed in challenging our arguably naïve postmodern assumptions that old age can and perhaps should be "youth with gray hair."

\section{Coupland \& Coupland, 1999 p. 186}

The ways in which older adults disclose their ages and formulate their age identities have attracted the attention of sociolinguistic scholars (Coupland \& Coupland, 1994; Coupland, Coupland, \& Giles,

\footnotetext{
* Corresponding author.

E-mail address: emmameichen@hotmail.com (M.-C. Lin).
} 
1989; Coupland, Coupland, Giles, \& Henwood, 1991; Taylor, 1992). Instead of viewing age identities as static, these studies suggest that social and personal age identities are negotiated and constantly renegotiated in a given context. As Coupland, Coupland, and Grainger (1991b, p. 101) noted, "aging itself is open to be defined interactionally." Age identity negotiations and presentations occur in the context of societal stereotypes of age. Conventional stereotypes of old age tend to be more negative than stereotypes of younger groups (e.g., Kite \& Johnson, 1988). However, research has identified multiple positive and negative subtypes of old age (e.g., Brewer, Dull, \& Lui, 1981; Brewer \& Lui, 1984; Hummert, 1990; Hummert, Garstka, Shaner, \& Strahm, 1994). Analysis of older adults' discourse on aging can reveal how they draw upon these stereotypes in building their age identities. The existing work on age identity discourse has primarily been conducted in either laboratory (e.g., Coupland, Coupland, Giles, et al., 1991) or institutional settings (e.g., Paoletti, 1998). The current study attempts to uncover the strategies that older adults employ to present age identity, but it is specifically interested in their discourse in a natural, noninstitutional setting: an on-line discussion forum.

\subsection{On-line discussion forums, older adults, and the negotiation of age identity}

Many older people are interested in learning about and are currently using computer systems. In the United States, approximately $29 \%$ of the aging population identify themselves as computer users (White et al., 1999). Further, adults over 65 are one of the fastest growing groups of web users, showing a 43\% increase in usage since 1994 (Adler, 2001; Wright, 2000). A national survey (Schwab et al., 1998) and The Pew Internet \& American Life Project (2001) reported that more than half of the wired senior population were on-line daily (e.g., for sending/receiving email messages, checking news/weather, researching health information). The Internet serves a social as well as informational function for older persons. It provides the opportunity for older adults to maintain existing social relationships (Harwood, 2004) and develop new ones (Cody et al., 1997; Furlong, 1989; Wright, 2000). One study has even found that Internet use increased the psychological well-being of older adults (White et al., 1999).

On-line interaction may be considered a type of conversation. E-mail parallels face-to-face interaction in its communicative features such as informality and emotional involvement (Baron, 1998). In addition, Colomb and Simutis (1996) suggested that group forums on the Internet allow for nonverbal communication through the use of emoticons and the like. Further, participants in e-mail conversations, like those in face-to-face interactions, develop interpersonal relationships and even close friendships (Baym, 1995, 1998; Wright, 2000). For discourse scholars, on-line interactions offer an advantage over face-to-face interactions: Because participants are able to express their viewpoints in e-mail messages without being interrupted, large discourse segments are available for analysis. Yet on-line interaction between older adults has received little empirical attention. For these reasons, an on-line discussion forum was selected as a legitimate and rich source for the study of age identity presentations.

\subsection{Discourse and age identity}

Age identity fits Tajfel's (1978, p. 63) definition of a social identity: "that part of an individual's selfconcept which derives from his [sic] knowledge of his membership in a social group(s) together with the 
value and emotional significance attached to that membership." According to the Social Identity Theory (SIT; Tajfel \& Turner, 1979), people are motivated to evaluate their group identity positively to protect their self-concepts. As a result, members of socially disadvantaged groups may employ various strategies to cope with their unfavorable status. These include strategies of social mobility (i.e., becoming a member of the higher status group), social competition (i.e., changing the existing social structure to improve group status), and social creativity (i.e., redefining the value of the group at a psychological level to improve group status). Inasmuch as social competition usually requires long-term collective action, individuals rely more on social mobility and social creativity.

In the case of age groups, negative age stereotypes give old age a lower status relative to middle age and create a corresponding challenge to the self-concepts of older individuals. Many older adults adopt social creativity strategies to respond to this threat, reconstructing the meaning of age at a psychological level to achieve positive personal and social identity (Harwood, Giles, \& Ryan, 1995). These strategies are manifested in daily discourse. For example, inasmuch as older people may not be able to compare their physical strength positively with that of other age groups, they may emphasize instead their ability to make good judgments. Therefore, using SIT, age-related discourse may exemplify strategies of social creativity.

Coupland, Coupland, Giles, et al. (1991) identified two processes through which older adults or their conversational partners make age identities salient. Age-categorization processes involved disclosing age by explicitly indicating age-related characteristics in talk. These processes include disclosing chronological age, age-related category/role references, and age-related experiences of illness and decline. Temporal framing refers to discursive strategies that locate events, persons, and the like within temporal space and, by implication, invoke the speaker's own age. Three subtypes fall into this category: Adding time-past perspective to current or recent events and topics (e.g., "I got my college degree in 1939 and we will have the 60th reunion next year"), association of the self with the past (e.g., "The Great Depression is still a reality for me"), and recognizing historical and cultural change (e.g., through reminiscence). Older people may introduce devices into their talk strategically to shift their age identity (even within the same conversation), depending upon their immediate social or interpersonal goals (Celejewski \& Dion, 1998). For example, Paoletti's (1998) study of older adults in an institutional setting provides an example of the social construction of age identity. Her participants described themselves as active and effective older adults. In doing so, however, they differentiated themselves from other older adults who they described as lonely, sick, and dependent; that is, they achieved a positive group identity by verbally distancing themselves from other older people.

On the other hand, Buchanan and Middleton (1995) examined identity building in reminiscence groups. They found that participants used the temporal framing strategy of reminiscence not to live in the past, but to create a shared group identity with other older people in the present. For example, by reminiscing about shared childhood experiences, participants recreated the meanings of their age group membership today. Coleman (1995) suggested that reminiscence promotes identity maintenance in older people by investing past achievement into current self-image. Through reminiscence, older people can collectively renew their group membership and add positive values to their current disadvantaged status as "old people." Building from this work, two research questions were addressed in the current study:

RQ1: What age identity themes are embedded in the on-line age-related discussion?

RQ2: How are age identities achieved (negotiated, maintained, and changed) in the discussion? 


\section{Method}

An Internet discussion forum offers the opportunity for unobtrusive observation of ingroup interaction. Such observation would be difficult to obtain from other methods. Discourse analysis was adopted as the most appropriate method for examining how meanings and values of age identities are constructed, negotiated, reinforced, or confronted in on-line language use. While age identity is commonly viewed as static, a discourse analysis approach highlights the ways in which that identity is instead dynamic and negotiated in conversation (Coupland, Nussbaum, \& Grossman, 1993). As Coupland (1988, p. 5) stated, "our social relationships, institutions, events and activities are mediated in. . language behavior. . .detailed inspections of language in use, its relationship to and constitution of meanings in context, will give access to the dynamic workings of social process." In addition, content analysis was used to verify categories identified in the discourse analysis and to investigate the relative frequencies with which particular age identity themes occurred in these on-line messages.

\subsection{Data source}

The data were gathered from a computer-mediated on-line community for older adults (SeniorNet). This site was selected because it was one of the first on-line communities to attract a substantial number of older people (Furlong, 1989) and currently has 39,000 registered members. It provides on-line discussions and technology learning centers for over-50s and supports research on aging and technology. Ito, Adler, Linde, Mynatt, and O'Day (1999) surveyed SeniorNet members and found that, in addition to retrieving information and overcoming fear of technology, joining on-line communities primarily provided a sense of social inclusion and identity formation. Several frequent participants seem to have formed friendships, and they post welcome messages to new participants (e.g., "Hello, Mary, I am glad you found us"). The main topic of the discussion forum examined in this study was "getting older, getting better." Therefore, it provided a natural context for age identities to emerge in the talk (albeit one that was intrinsically positively oriented, as will be discussed in detail later).

\subsection{Sample}

Messages posted from the beginning of the discussion group in September 1997 to September 1999 were included in the analysis $(N=550)$. The data were downloaded from the Internet as a public record. To guard against the possibility that messages might be linked to individuals, names and other individuating information are deleted or changed in this report. A caveat of using this type of sample is the limited generalizability of the results. Because survey data indicates that more than half of the computer users among older adults have a college education (Adler, 2001; White et al., 1999), the participants in this on-line discussion forum were likely to be a highly educated and select group. Naturally, we make no claims as to the representativeness of the participants in this group, either in terms of older computer users or older people more generally.

\subsection{Analysis}

A qualitative discourse analysis was utilized to examine discursive manifestations of age identity in peer-elderly interaction. The analysis was done inductively following the guidelines of Potter and 
Wetherell (1987). First, treating each message as a unit, 1-3 primary topics associated with age identity representations were recorded on a spreadsheet. Age identity representations could be embedded in a single sentence, in a series of statements, or in a whole message. A topic that appeared across several messages was categorized as a theme.

Second, the framing tactics of the age identity themes were identified. This involved examining the ways in which each theme evolved in the flow of the messages. Particular linguistic patterns that emerged and helped achieve an age identity theme were considered framing tactics.

The validity of the age identity themes was established using the traditional approaches in discourse analytic research: (1) an age identity theme was recognized based on instances across multiple messages; and (2) themes were compared and contrasted to those of previous studies on aging-related discourse. In addition, a content analysis was conducted to verify our linking of discourse excerpts to themes and to allow investigation of the frequency with which discussion members incorporated these themes into their messages. The following section describes the coding sample, the coding scheme, and the coding procedure for the content analysis. The results of the content analysis are reported as we discuss each age identity theme.

\subsubsection{Coding sample}

Because the 550 messages collected included age-related and non-age-related talk (e.g., greeting, car problems, current news, or weather), the first step involved determining whether a message was relevant to aging. The definitions for age-relevant/irrelevant categories were drawn from the dimensions of elderly identity marking (e.g., age-related category/role reference) of Coupland, Coupland, Giles, et al. (1991) and Giles, Coupland, Coupland, Williams, and Nussbaum's (1992), and the previous literature on older age identity (e.g., age-related health problems or issues, reminiscences). Two undergraduate coders received training on using the protocol and applying the definitions. Intercoder reliability (based on independent coding of 60 messages) was acceptable (90\% agreement, Scott's $\mathrm{Pi}=.79)$. Disagreements were discussed and resolved. Of the 550 messages, 315 were age-relevant and were subject to thematic content analysis.

Table 1

Frequencies of age identities in the on-line discussion forum

\begin{tabular}{|c|c|c|c|}
\hline Age identity & Frequency $(N=255)$ & Percentage & Rank \\
\hline \multicolumn{4}{|l|}{ Positive age identity themes } \\
\hline A mind-over-body attitude & 84 & 32.9 & 1 \\
\hline Active engagement & 47 & 18.4 & 2 \\
\hline Wisdom and maturity & 38 & 14.9 & 3 \\
\hline The freedom of age & 9 & 3.5 & 7 \\
\hline \multicolumn{4}{|l|}{ Negative age identity themes } \\
\hline Physical decline & 34 & 13.3 & 4 \\
\hline A sense of loss & 15 & 5.9 & 5 \\
\hline The resistance of aging & 14 & 5.5 & 6 \\
\hline \multicolumn{4}{|l|}{ Others } \\
\hline Positive & 11 & 4.3 & \\
\hline Negative & 3 & 1.2 & \\
\hline
\end{tabular}




\subsubsection{Coding of age identity themes}

An operational definition for each age identity theme was developed based on the discourse analysis results and discussions with the two coders during practice coding. An "other" category was included for messages that did not fit into any of the identity themes. Coders were instructed to select the primary theme present in each message. Sixty messages were randomly selected from the coding sample of 315 and used for two rounds of practice. The two coders then coded the age identity themes in the remaining 255 messages, overlapping on 51\% $(n=130)$ for the purposes of assessing intercoder reliability $(86 \%$ agreement, Scott's $\mathrm{Pi}=.80)$. Frequencies of the themes are presented in Table 1.

\section{Results}

Our analyses suggest that aging is experienced as a struggle or dialectic between declining mental capabilities/health and satisfaction at being able to control one's life. The discourse analysis approach helps us see the identity negotiation dialogue occurring in the forum's "conversation." The participants' discourse was centered on two questions: "What is old?" and "Are we old?" In answering these questions, participants appeared to draw on four positive and three negative themes. The results will be discussed in terms of discourse features and framing tactics. The content analysis results indicated that positive age identities were more frequently presented $(69.7 \%)$ than the negative ones $(22.7 \%$; see Table 1) were. Approximately $5.5 \%$ of the messages were coded into the "other" category ( $4.3 \%$ positive, and $1.2 \%$ negative).

\subsection{Positive themes}

\subsubsection{A mind-over-body attitude}

This theme was the most frequent in these messages, occurring in $32.9 \%$ of the messages. The central premise of this theme is that by maintaining a positive attitude, older people can overcome unpleasant experiences of aging. Writers stressed the importance of positive attitudes in growing old gracefully in the face of ailments and the loss of youth. For example, "Pessimism is deadly, it also can contribute to illness being more uncomfortable than it has to be. . thank goodness we can change our thoughts and change our feelings immediately" (\#92); “The body has great healing capacities, but the mind must cooperate and give it a chance" (\#308).

The mind-over-body attitude was often framed by personal references to support the writer's belief (e.g., work experiences in nursing homes or with aging family members; quotes and stories from inspirational books or poems). These anecdotes or stories were used by the writers to show that valuable insights can be gained by encountering frustration and difficulties in late life with "determination" (\#92) and "dignity" (\#101). One writer asserted that "growing older is to introduce gentleness and dignity, always dignity" (\#101).

Further, family members with longevity were frequently used to illustrate how a mind-over-body attitude can work and that this attitude also represents the writer's expectation of the ideal aging process. As one writer offered, "With a mother who is 89 , I have to agree, her health problems are difficult to see on a physical level. . .but her mind, her wisdom, her forgiving of herself of past errors. . .she is the golden of golden age in our family..." (\#96). 


\subsubsection{Active engagement}

This theme was the second most frequent presented in these messages, constituting $18.4 \%$ of the sample. Keeping physically fit, socially involved, and intellectually active were repeatedly mentioned as ways to get better as one gets older. For example, "I am one of the exercisers who absolutely refuses to give in to aches and pains. I will continue fitness walking and bicycling just as long as I can" (\#6). Others stressed the engagement that comes from social activities and new experiences, for instance, "I am finishing my 'tour of duty' in the chorus of 'how to succeed in business without really trying' tomorrow. All in all, I am glad I did it" (\#163). For other participants, active engagement entailed service to others: "I volunteer my services whenever needed to the office that manages our apartments to act as receptionist, to do clerical duties, assist a resident whenever necessary, to attend meetings" (\#182). Stories about on-going intellectual development were also part of this theme (e.g., returning to school: "After 46 years I finally went to high school and on June 4th of this year, I graduated!" \#227). Another common achievement mentioned was the acquisition of computer skills, as the writers expressed their belief that Internet services helped them to stay current, "I'm well past the 70 mark and am probably as addicted to this computer and the Internet as one can get" (\#359).

Positive identities of active engagement were framed through implicit contrasts with negative age stereotypes of withdrawal and decline (e.g., "I am 64, and still working full-time. I cannot imagine really 'retiring' and not being productive in some manner," \#4; "I watch my 84 year old father. . and am constantly amazed at what he is still involved in," \#9). The word "still" and the phrase "amazed at" reflect the double-faced age identity described by Paoletti (1998); that is, these writers formulated a positive age identity by marking their behaviors' deviation from the accepted negative stereotypes about aging: declining health, uselessness, and isolation. The disclosure of their own or another's chronological age in the beginning of these examples was consistent with other messages using this framing tactic. Thus, this disclosure may be the first step in this framing tactic, setting the boundary conditions that allow the writer to accomplish a positive age identity in the remainder of the message (Coupland et al., 1989).

Other participants established a positive age identity by more explicitly contrasting themselves with negative stereotypes of others in their age group. As one participant inquired, "Are you able to relate to those people [in our age bracket] who are so bored, who wake up each morning saying 'gosh, another day. What will I do today?" (\#311). This framing tactic is another example of the doublefaced age identity of Paoletti (1998). Ironically, in using this tactic, writers accomplish a positive identity by reinforcing negative age stereotypes and distancing themselves from their age peers. Illustrating this negative assessment of other older persons, several writers used the terms "gripe session" and "gripe factory" (\#6) to describe older people in the local senior center, characterizing the patrons of the senior as continuously complaining about issues such as taxes or city infrastructure. Many expressed sentiments similar to the following: "My husband cannot bear to be around 'old people"" (\#375).

\subsubsection{Wisdom and maturity}

This theme created a positive age identity based on the accumulation of life experiences. It constituted $14.9 \%$ of the messages. Writers characterized themselves as having achieved wisdom as they triumphed over bad judgments and mistakes made earlier in their lives. For example, one wrote that a birthday was to "celebrate my accumulation of wisdom" (\#260). The words "more" and "less" were used to show how the participants had improved over time: "I am more calm, content, less 
critical, less expert and more curious. I carry the same heavy baggage but I set it down quietly and wait for a better moment" (\#109). Participants also enacted wisdom by using quotations or sharing anecdotes and theories on the values of life. These were acknowledged and praised by others in the discussion with responses such as "what wisdom!" (\#247) and "you are an inspiration to us all!" (\#37). A metaphor, "The treasure house of wisdom," was associated with this theme. While personal wisdom was valued, messages around the treasure house metaphor described how older adults' wisdom was also a societal resource (e.g., "Why not use the treasure house of wisdom we have," \#155; "a large proportion [of older people] are wise and experienced enough to improve on the poor quality of goods and services in today's America not to mention improve on family and moral values that are deteriorating so fast," \#154).

\subsubsection{The freedom of age}

This theme reflected writers' feelings that age freed them from socially prescribed duties or roles. This was the least frequent theme (3.5\%). Some welcomed this freedom because it relieved stresses experienced at earlier ages (e.g., "I found a way to really enjoy the Big 70. Just go out that day and buy a new Cadillac like I did on my 70th. You will enjoy it then," \#91). For others, the freedom of age meant embracing risk and adventure. One jet-skiing participant offered the following perspective: "Hey, at my age, I don't need to be careful. It is all down hill anyway, and I have no kids to support. This is the time to defy danger" (\#244). These statements conveyed joy in being free from responsibilities and consequences.

Two framing tactics were used to accomplish this. First, the theme was framed not just as freedom, but as freedom that had been earned. Writers described their feelings of contentment with their lives as they now could attend to their own needs and desires rather than those of other people such as children or coworkers. An impression of positive thinking was conveyed in these messages, which was similar to the second theme - active engagement. The phrases, "writing my own scripts" and "writing the whole new book" were employed to further stress the freeing power of age. The second framing strategy is captured by the question "at my age, what do I have to lose?" This remark was used to legitimize stereotype-defying behavior such as having a red or purple casket (\#61), driving a red truck (\#40) or sports car (\#91). The aging self is presented positively as embracing opportunities to enjoy life and attempt risky behavior.

\subsection{Negative themes}

\subsubsection{Physical decline}

This theme (13.3\%) involved a direct challenge of the assumptions underlying the positive mind-overbody attitude theme: "Every time I hear that phrase 'golden age' I want to puke, it's such a lie for many of us" (\#97). Other messages took a slightly less direct approach, but with similar effect (e.g., "My body doesn't want to do what it used to nor does it have the opportunities. Who are we kidding around here. . Pollyanna maybe but not [the writer's name]," \#95). Two framing tactics were associated with this theme. One involved the personification of age (e.g., "It [age] is the enemy," \#146; "age creeps upon you," \#245). In messages such as these, writers portrayed older people as vulnerable and helpless before a powerful antagonist - age. The second involved appropriating and explicitly confronting the positive age identity discourse. The notion of age being "golden" was often held up to a reality check, as in the following: "Is it golden for disabled and people who have disease because of aging?" (\#99). 
These messages carried an undertone of sarcasm through their use of "golden" to undercut the validity of the mind-over-body attitude. One writer stated, "I don't agree that suffering and loneliness are OK even golden for having lived a good life" (\#102).

\subsubsection{A sense of loss}

The second most frequent negative theme highlighted nonphysical aspects of loss in later life (5.9\% of the total messages). These include role loss (e.g., widowhood, retirement), financial insecurity, and loneliness due to social disconnection. As one writer asked, "Just how can one grow old gracefully and be happy when one has so little and no one to talk to?" (\#219). Old age was described as a process of experiencing gradual loss, which in turn caused stress, frustration, and depression. For some participants, the perception that their personal or interpersonal value had diminished had adverse effects on their emotional health.

The framing tactics for these messages usually included short questions, as in \#219 above, and a pessimistic tone, as in \#469 (below). References to emotions were common in questions to other participants ("Does anyone share this feeling?" \#219) and descriptions of the writer's own emotional state ("feeling sad," \#469). The comments suggested that these contributors were in a transition in which they attempted to seek emotional support or sound advice, as illustrated in \#469: "I'd love to talk to anyone: retirement. Right now, I am feeling very sad."

\subsubsection{Resistance to aging}

The last negative theme (5.5\%) indicated a strong preference for youth over old age. Messages in this category revealed a linguistic distancing from or rejection of chronological age by specifying a younger subjective or preferred age. For example, one writer described herself as "a 24-year-old woman stuck in a 63 year old body" (\#370), and another wrote, "I have been 29 for 33 years and intend to stay [29] for at least 33 more" (\#30). The ages selected were associated with particular traits such as curiosity and playfulness. For example, "I am 63 legally, 14 when I kid around...I am at least 80 if my arthritis is bugging me" (\#360).

The framing strategy used in these messages involved the juxtaposition of the writers' actual and preferred ages, with the negative aspects of aging highlighted in that juxtaposition (e.g., the writer of \#370 (above) feeling "stuck" in her 63-year-old body, emphasizing her view that the physical aspects of aging are problematic). Another forum contributor was even more direct about preferring to be younger: "I liked being thirty-five, don't much appreciate approaching twice that" (\#86). The preferred ages tended to cluster around later young adulthood and mid-middle age, which is usually regarded as a period of "progressive achievement and increasing autonomy... of greatest productivity and of major rewards" (Neugarten \& Datan, 1996, p. 137). Thus, this framing strategy functions paradoxically to create a positive age identity for writers, although it stresses that aging is negative. Contributors acknowledge their own physical aging, while denying that their chronological ages are accurate assessments of their inner selves.

\section{Discussion}

Three of the positive themes illustrated the writers' recognition and acceptance of old age but emphasized their relative good health, mental power, and/or contributions to the community. Each 
showed older individuals as participants in and contributors to the larger social arena. In contrast, the last positive theme, freedom of age, associated old age with opportunities to explore and experiment, positively redefining the meaning of old age. This theme focused on personal needs and aspirations more than the other three. By framing freedom as earned from a lifetime of responsible behavior, forum participants justified their behaviors that were depart from age-appropriate norms. In doing so, they may have been drawing an implicit contrast between their newfound freedom and the self-indulgence for which the young are often criticized.

The first two negative themes, physical decline and a sense of loss, described aging as a process of decline in mental/physical capabilities and disengagement from society (Nussbaum, Pecchioni, Robinson, \& Thompson, 2000). In these themes, aging is accepted with a firm belief that nothing can be done to make it better (physical decline) or responded to with confusion and frustration (a sense of loss). By expressing the difficulties in daily life, writers implied that the positive thinkers were overly optimistic and in denial. Other contributors were searching for counseling or raising questions that might sound discouraging to positive thinkers. A subtle difference can be seen between messages in the physical decline and a sense of loss themes: the former adopted an argumentative attitude, while the latter attempted to direct the discussions to a deeper emotional level. The last negative theme, resistance to aging, is similar to the positive mind-over-body attitude, in that both involve writers using "mental power" to cope with the negative aspects of aging. The difference lies in the way in which it is done. A mind-over-body attitude does not disassociate writers from their current age group membership. In contrast, the resistance to aging approach linguistically and psychologically releases writers from old age and identifies them as belonging to a younger age group.

\subsection{Age identity and health identity}

One negative and two positive themes (active engagement, a mind-over-body attitude, physical decline) shared a focus on the discursive link between age and health. As noted by Coupland and Coupland (1995, p. 90), "Health and age. . become tokens in a rather ritualized series of lay exchanges about age that are very characteristic of everyday talk." Our findings confirmed that health is a common topic in peer-elderly discourse that is crucial in older adults' identity-related communication. In our data, $62.8 \%$ of the messages contained some version of a theme that related health and age identities, demonstrating that health in later life is one of the most important sources and indications of an older person's age identity.

The two positive themes depicted two different approaches to the age-health link. The active engagement theme portrayed lively images (e.g., busy schedule and activities). A determined attitude against ageism was associated with balancing social life and exercise. The other positive theme, a mindover-body attitude, described a scenario where the struggle of aging was managed with a confident disposition. In contrast, the negative physical decline theme presented a relatively depressing scenario where aging was accepted with negative and fearful attitudes. These three themes shared an assumption that physical deterioration is an undeniable fact. They are differentiated in terms of the expressed belief in whether it is possible to mentally transcend that decline. Moody's (2001-2) discussion of life extension medicine and technology may echo a similar dialectic between age identity and health. As we confront more extensive technological means to increase life expectancy, feelings of ambivalence about aging are foregrounded. 


\subsection{Age identity and SIT}

According to SIT (Tajfel \& Turner, 1979), members of socially disadvantaged groups use a variety of methods of coping with their lower status to achieve a more positive group identity. Two of those methods, social creativity and social mobility, are ways that group members can acknowledge negative stereotypes of their group but claim that they do not apply to them. Three themes identified in this forum exemplified social creativity strategies: mind-over-body attitude, wisdom and maturity, and active engagement. For example, the mind-over-body attitude messages suggest that, with a psychological reorientation, older persons can make the experience of age positive, therefore changing the value of group membership in the older age category from negative to positive. Likewise, the wisdom and maturity theme reframes old age as a positive category by emphasizing a dimension on which old age is traditionally more valued than youth. A third social creativity strategy is to distance oneself from certain subgroups of the ingroup (Branscombe, Ellemers, Spears, \& Doosje, 1999), as in the active engagement theme. As with some of the older individuals observed by Paoletti (1998, p. 20) this distancing was "achieved by association of the category 'old' with its negative stereotypical attributions but designating other members with it." In our data, certain participants constituted a new definition of old in their discourse, one that was distinct from the negative age stereotypes that aptly describe "other" older people (Phillipson, 1998). As Table 1 shows, 165 messages $(66.3 \%)$ employed one of these three themes that constitute social creativity strategies, suggesting that making age into a positive group was important to the contributors to the forum.

In contrast, only one theme, the resistance to aging, can be classified as a social mobility strategy (nine messages, 3.5\%), albeit at a psychological level, with its emphasis on a desire for youth and youthful traits. Writers who offered this theme achieved a positive age identity by rejecting their own age outright and aligning with teenagers, young adults, or the middle-aged. The expressions "stay young" and "think young" occurred in these messages as a way to overcome the immutable facts of physical aging. Ironically, while these messages reject traditional age stereotypes, they also reinforce the norms and conventional stereotypes of all age groups. A positive identity is achieved individually by associating with youth, but it does not enhance the conception of aging in a collective or group sense. Perhaps illustrating the reality that true social mobility (i.e., becoming an actual younger person) is not available to the older persons, only nine $(3.5 \%)$ messages fit this theme.

\subsection{Limitations and future directions}

The first limitation of this study is that the discussion forum studied had an explicitly positive orientation to aging. Older adults who agree with this attitude are probably more likely to post to the forum and may create a group norm that negative comments are not welcome. Comments such as "I finally found a positive area to hang my hat!" (\#223) appeared in the messages, emphasizing that being positive was an evident norm in this discussion group. Second, using an on-line discussion as a data source for exploring age identity probably limits the subject population to wealthier and more educated elders (Adler, 2001; White et al., 1999), as noted in the Method section.

Future studies should continue to explore on-line manifestations of age identity. The findings of the current study provide evidence that the Internet is a rich communication medium that older people use to reach out to peers for support and to express their identities in a variety of contexts (Harwood, 2004). 
Such research will grow in importance as more older people get "wired." Giddens' (1979) structuration theory has been suggested as a useful perspective for research on intergenerational communication and age identity (Williams \& Nussbaum, 2001). The central idea of structuration is the notion of the duality of structure - the interaction between existing social practices and people's individual actions. From this perspective, age identity presentation can be understood as a simultaneous negotiation of societal age stereotypes and one's self-construction. This is an explicitly communicative orientation to age identity. The discursive realizations of age identities both reveal and perpetuate the underlying culturally grounded age-related values. Such realizations might be usefully examined in intra- versus intergenerational discourse (e.g., Coupland, Coupland, \& Grainger, 1991), including the development of intergenerational relationships. Further work should also examine other important age identity themes (e.g., those associated with the grandparent-grandchild relationship, which did not emerge in these data; see Harwood \& Lin, 2000).

In conclusion, various age identities were honored, endorsed, and challenged in our data. Negative age stereotypes were positively managed, and positive identities were constructed within a negative framework. These themes and framing tactics illustrate the complexity of age identity - it is a mix of chronological, health, and personal identities, and these identities are interwoven and negotiated in the discursive process. SIT provides a useful framework to understand the broader identity goals being served by the rather specific strategies uncovered. In today's society, there are people who are suffering from pain and infirmities due to aging, people who turn the infirmities of aging into opportunities for experimentation and participation, and people who do not experience infirmity. There are difficulties in aging, but they can be managed. As one writer said, "If you are not getting older, you are dead" (\#76).

\section{Acknowledgements}

Preparation of this manuscript was supported by NIA/NIH Grant 16352.The authors thank Dr. Adrianne Kunkel for her suggestions on an earlier draft of this paper and Robert Shiller and Angie Wright for their assistance in coding.

\section{References}

Adler, R. P. (2001). Older adults and computers: Report of a national survey [On-line]. Available: http://www.seniornet.org/ php/default.php?PageID $=5476$

Baron, N. (1998). Letters by phone or speech by other means: The linguistics of email. Language and Communication, 18, $133-170$.

Baym, N. K. (1995). The emergence of community in computer-mediated communication. In S. G. Jones (Ed.), CyberSociety (pp. 138-163). Thousand Oaks, CA: Sage.

Baym, N. K. (1998). The emergence of online community. In S. G. Jones (Ed.), Cybersociety 2.0: Revisiting computermediated communication and community: New media cultures, vol. 2 (pp. 35-68). Thousand Oaks, CA: Sage.

Branscombe, N. R., Ellemers, N., Spears, R., \& Doosje, B. (1999). The context and content of social identity threat. In N. Ellemers, R. Spears, \& B. Doosje (Eds.), Social identity: Context, commitment and content (pp. 35-58). Oxford: Blackwell.

Brewer, M. B., Dull, V., \& Lui, L. (1981). Perceptions of the elderly: Stereotypes as prototypes. Journal of Personality and Social Psychology, 41, 656-670. 
Brewer, M. B., \& Lui, L. (1984). Categorization of the elderly by the elderly. Personality and Social Psychology Bulletin, 10, $585-595$.

Buchanan, K., \& Middleton, D. (1995). Voices of experience: Talk, identity and membership in reminiscence groups. Aging and Society, 15, 457-491.

Celejewski, I., \& Dion, K. K. (1998). Self-perception and perception of age groups as function of the perceiver's category membership. International Journal of Aging and Human Development, 47, 205-216.

Cody, M. J., Wendt, P., Dunn, D., Pierson, J., Ott, J., \& Pratt, L. (1997, May). Friendship formation and creating communities on the Internet: Reaching out to the senior population. Paper presented at the Annual Meeting of the International Communication Association, Montreal.

Coleman, P. G. (1995). Facing the challenges of aging: Development, coping, and meaning in life. In J. F. Nussbaum, \& J. Coupland (Eds.), Handbook of communication and aging research (pp. 6-39). Mahwah, NJ: Lawrence Erlbaum Associates.

Colomb, G. G., \& Simutis, J. A. (1996). Visible conversation and academic inquiry: CMC in a culturally diverse classroom. In S. C. Herring (Ed.), Computer-mediated communication: Linguistic, social and cross-cultural perspectives (pp. 203-224). Philadelphia: John Benjamins Publishing.

Coupland, J., \& Coupland, N. (1994). Old age doesn't come alone: Discursive representations of health-in-aging in geriatric medicine. International Journal of Aging and Human Development, 39, 81-95.

Coupland, J., Coupland, N., Giles, H., \& Henwood, K. (1991a). Formulating age: Dimensions of age identity in elderly talk. Discourse Processes, 14, 87-106.

Coupland, J., Coupland, N., \& Grainger, K. (1991b). Intergenerational discourse: Contextual versions of aging and elderliness. Aging and Society, 11, 189-208.

Coupland, N. (1988). Introduction: Towards a stylistics of discourse. In N. Coupland (Ed.), Styles of discourse (pp. 1-19). New York: Croom Helm.

Coupland, N., \& Coupland, J. (1995). Discourse, identity and aging. In J. F. Nussbaum, \& J. Coupland (Eds.), Handbook of communication and aging research (pp. 79-104). Mahwah, NJ: Lawrence Erlbaum.

Coupland, N., \& Coupland, J. (1999). Ageing, ageism and anti-ageism: Moral stance in geriatric medical discourse. In H. E. Hamilton (Ed.), Language and communication in old age: Multidisciplinary perspectives (pp. 136-176). New York: Garland Publishing.

Coupland, N., Coupland, J., \& Giles, H. (1989). Telling age in later life: Identity and face implications. Text, 9, 129-151.

Coupland, N., Nussbaum, J. F., \& Grossman, A. (1993). Introduction: Discourse, self and the lifespan. In N. Coupland, \& J. F. Nussbaum (Eds.), Discourse and lifespan identity (pp. xx-xxviii). Newbury Park, CA: Sage.

Furlong, M. S. (1989). An electronic community for older adults: The SeniorNet network. Journal of Communication, 39 , $145-153$.

Giddens, A. (1979). Central problems in social theory: Action, structures and contradiction in social analysis. Berkeley, CA: University of California Press.

Giles, H., Coupland, N., Coupland, J., Williams, A., \& Nussbaum, J. F. (1992). Intergenerational talk and communication with older people. International Journal of Aging and Human Development, 34, 271-297.

Harwood, J. (2004). Relational, role, and social identity as expressed in grandparents' personal web sites. Communication Studies, 55(2), 268-286.

Harwood, J., Giles, H., \& Ryan, E. B. (1995). Aging, communication, and intergroup theory: Social identity and intergenerational communication. In J. F. Nussbaum, \& J. Coupland (Eds.), Handbook of communication and aging research (pp. 133-160). Mahwah, NJ: Lawrence-Erlbaum Associates.

Harwood, J., \& Lin, M. -C. (2000). Affiliation, pride, exchange, and distance in grandparents' accounts of relationships with their college-aged grandchildren. Journal of Communication, 50, 31-47.

Hummert, M. L. (1990). Multiple stereotypes of elderly and young adults: A comparison of structure and evaluations. Psychology and Aging, 5, 183-193.

Hummert, M. L., Garstka, T. A., Shaner, J. L., \& Strahm, S. (1994). Stereotypes of the elderly held by young, middle-aged, and elderly adults. Journal of Gerontology: Psychological Science, 49, 240-249.

Ito, M., Adler, A., Linde, C., Mynatt, E., O’Day, V. (1999). Broadening access: Network research for diverse communities [On-line]. Available: http://www.seniornet.org/php/default.php?PageID $=5495$

Kite, M. E., \& Johnson, B. T. (1988). Attitudes toward older and younger adults: A meta-analysis. Psychology and Aging, 3, $233-244$. 
Moody, H. R. (2001-2, Winter). Who's afraid of life extension. Generations, XXV(4), 33-37.

Neugarten, B. L., \& Datan, N. (1996). The middle years. In D. A. Neugarten (Ed.), The meaning of age: Selected papers of Bernice L. Neugarten (pp. 135-169). Chicago: University of Chicago Press.

Nussbaum, J. F., Pecchioni, L. L., Robinson, J. D., \& Thompson, T. L. (2000). Communication and aging (2nd ed.). Mahwah, NJ: Lawrence Erlbaum Associates.

Paoletti, I. (1998). Being an older woman: A study in the social production of identity. Mahwah, NJ: Lawrence Erlbaum Associates.

Phillipson, C. (1998). Reconstructing old age: New agendas in social theory and practice. Thousand Oaks, CA: Sage.

Potter, J., \& Wetherell, M. (1987). Discourse and social psychology: Beyond attitudes and behavior. London: Sage.

Schwab, C. \& Co. for SeniorNet. (1998). Research on seniors' computer and Internet usage: Report on a national survey [On-line] Available: http://www.seniornet.org/php/default.php?PageID $=5474$

Tajfel, H. (1978). Differentiation between social groups: Studies in the social psychological of intergroup relations. London: Academic Press.

Tajfel, H., \& Turner, J. C. (1979). An integrative theory of intergroup conflict. In W. C. Austin, \& S. Worchel (Eds.), The social psychology of intergroup relations (pp. 33-53). Monterey, CA: Brooks/Cole.

Taylor, D. M. (1992). Elderly identity in conversation: Producing frailty. Communication Research, 19, 493-515.

The Pew Internet and American Life Project. (2001). Wired seniors [On-line]. Available: http://www.pewinternet.org/reports/ toc.asp?Report $=40$

White, H., McConnell, E., Clipp, E., Bynum, L., Teague, C., Navas, L., Craven, S., \& Halbrecht, H. (1999). Surfing the net in later life: A review of the literature and pilot study of computer use and quality of life. The Journal of Applied Gerontology, $18,358-378$.

Williams, A., \& Nussbaum, J. F. (2001). Intergenerational communication across the life span. Mahwah, NJ: Lawrence Erlbaum Associates.

Wright, K. (2000). Computer-mediated social support, older adults, and coping. Journal of Communication, 50, 100-118. 